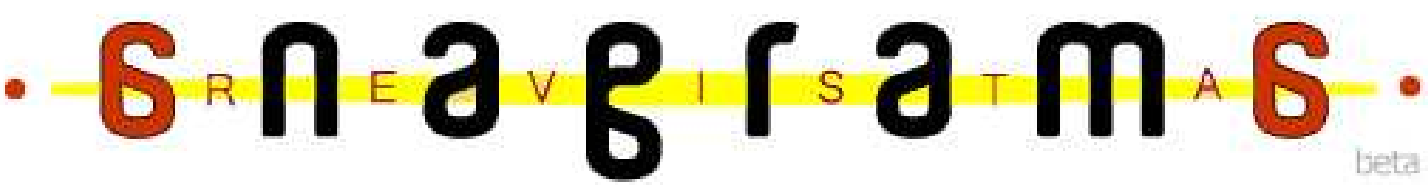

0 Processo de Legitimação Organizacional no Cenário

\section{Contemporâneo das Tecnologias da Informação e Comunicação}

\section{Jones Machado ${ }^{7}$ \\ Elisângela Carlosso Machado Mortari}

\section{Resumo}

O presente artigo encontra-se dividido em duas partes e pretende discutir como o processo de legitimação organizacional se apresenta no cenário contemporâneo, a partir da evolução das tecnologias digitais da informação e comunicação, essas consideradas dispositivos que permitem novas possibilidades de interação das organizações com seus públicos. Tais relações de interatividade são estabelecidas via estratégias de comunicação numa ambiência digital, principalmente pelo sistema da Internet, entendida neste estudo como um espaço no qual se constroem a visibilidade midiática e a legitimação das organizações.

Palauras-chaue: Estratégias de comunicação; Interação; Legitimação institucional; Tecnologias digitais da informação e comunicação; Visibilidade midiática.

\section{nouas formas de interação}

A evolução das tecnologias digitais da informação e comunicação (TICs) ${ }^{3}$ vem possibilitando aos profissionais gestores da comunicação e às organizações do cenário contemporâneo novas formas de interagir e legitimar-se junto à sociedade.

Ao considerar a essência da comunicação organizacional como o estabelecimento de relações interativas com públicos específicos e a busca contínua de legitimação, de aceitação perante a sociedade, vale ressaltar que a inovação das TICs potencializa a comunicação; no sentido de que integra discursos, complexifica processos, dinamiza a

\footnotetext{
${ }^{1}$ Graduando do $7^{\circ}$ semestre do Curso de Comunicação Social - Habilitação em Relações Públicas da Universidade Federal de Santa Maria (UFSM) - RS / E-mail: jonesm2@ hotmail.com

${ }^{2}$ Doutora em Comunicação e Cultura pela Universidade Federal do Rio de Janeiro (UFRJ) e Professora Adjunta do Departamento de Ciências da Comunicação da UFSM. E-mail: elimortari@hotmail.com

${ }^{3}$ Utilizarei o termo TICs para indicar as tecnologias digitais da informação e comunicação.
} 
construção do processo comunicacional das organizações e oportuniza novas estratégias de visibilidade midiática.

Na contemporaneidade, a informação continua sendo mais do que nunca elemento de grande valor que ativa o processo de relacionamento. Em face disso, vemos o uso recorrente do termo sociedade informacional em referência a uma nova forma de organização social caracterizada pela estrutura reticular e pela convergência de tecnologias, esta entendida como uma hibridação midiática; a integração de dispositivos midiáticos num ambiente digital. Desse modo, a capacidade e a forma do ser humano de processar informações mostram-se modificadas, ao mesmo tempo em que a linguagem comunicacional deve ser adaptada em decorrência das novas possibilidades de geração, processamento e transmissão de informações que se apresentam, visto que "as técnicas de comunicação de cada época contribuem para a constituição de diferentes formas de sociabilidade" (Barichello, 2001: 27).

Antes de tudo, é preciso considerar a informação como matéria-prima fundamental para as Relações Públicas, baseando-se na cultura e nas atuais formas possíveis de sociabilidade, para assim, as organizações proporem estratégias que estabeleçam relações interativas no meio digital. Com relação ao conteúdo informacional, o teórico Patrick Charaudeau (2007) atenta para o fato de que a informação, por se caracterizar como pura enunciação depende da circunstância de enunciação e do dispositivo no qual é posta em funcionamento. Na mesma direção, Gary Kreps (1995) lembra que é preciso reconhecer a individualidade dos comunicadores e os distintos significados criados em resposta aos fenômenos. Por isso que, com as formas de comunicação emergentes mostra-se imperiosa a preocupação com aspectos como o tratamento da informação e a escolha das estratégias discursivas que garantam visibilidade favorável às organizações. Segundo Barichello (2009),

[...] é preciso considerar a comunicação mediada por computador e suas propriedades, tanto na utilização quanto na formulação de novos modelos, de forma a contemplar a convergência das ações proporcionadas pelo suporte reticular e a interatividade que ele proporciona, fatores que reconfiguram, queiramos ou não, as tipologias de fluxos comunicacionais atualmente existentes (2009: 343).

A comunicação digital possibilitada pelo uso dos meios eletrônicos digitais, principalmente pelo sistema da Internet, desponta como ambiência flexível e dinâmica, em caráter de permanente mutação e que oportuniza aos indivíduos espaço de geração e compartilhamento de informações e significados. Nesse sentido, percebe-se tal ambiência 
mediada por tecnologias de comunicação não como um lugar de transmissão linear de informações, mas como campo de interação simbólica em que as relações espaciotemporais são reordenadas e provocam um deslocamento da experiência do indivíduo do local efetivo de vivência. O espaço de fluxos, pois; substitui o espaço de lugares que por tempos predominou na forma de se comunicar na sociedade.

Com o surgimento dessa nova modalidade de território organizado em rede, o virtual; graças ao desenvolvimento dos meios de comunicação, foi possível a aceleração dos fluxos e a interatividade a distância. A noção de espaço e de tempo enraizados na experiência humana é sobreposta pelos circuitos de conexão e fluidez da informação. Desse modo, por meio das possibilidades de interação que tal território virtualizado oferece às organizações, os profissionais de comunicação contemporâneos devem lançar mão de estratégias planejadas específicas e adequadas, como forma de manter relações com determinados públicos em busca de visibilidade e legitimação institucional.

Nesse contexto, pode ser trazido o modelo simétrico de duas mãos de prática das relações públicas elaborado por Grunig e Hunt (1984 apud FERRARI, 2008), no qual os autores propõem a manutenção da troca de informações (prática de relacionamentos) com os públicos estratégicos e a busca da satisfação mútua por meio da negociação e do consenso. Relacionando tais ações aos meios tecnológicos que permitem a interação entre organização e públicos de interesse, é necessário um exercício de correlação entre a ciência das TICs e a arte de comunicar. Com relação a isso, Elisabeth Saad Corrêa salienta que

[...] muito antes do pensamento comunicacional estratégico, temos que encontrar o equilíbrio entre constatações típicas da ciência, a exemplo dos princípios, das recorrências fundantes, das explicações, das descobertas e das análises e a característica criativa da arte de comunicar, em uma rotina na qual predominam as práticas, a experimentação de performances, a ação, a invenção, a síntese e a construção (2009: 325).

Nessa direção, aponto alguns aspectos que devem ser considerados na atividade de Relações Públicas, gerenciadora da comunicação organizacional, a fim de que as estratégias para a ambiência digital sejam realmente compartilhadas com o público pretendido. Entende-se por ambiência digital neste estudo, uma estrutura complexa de comunicação capaz de gerar fluxos de informação e proporcionar redes de interatividade. É preciso atentar, primeiramente, se há acesso aos dispositivos eletrônicos - a saber, o computador - e se há o hábito/cultura do uso de tal suporte de mídia pelos indivíduos de modo que não se caracterizem situações de exclusão digital - e até mesmo comunicacional. Valer-se de linguagem adequada com o público e escolher dentre as opções tecnológicas as 
que atendem aos propósitos, intenções e necessidades tanto do proponente da comunicação quanto do outro com quem se está em relação, também se revelam aspectos indispensáveis para que as trocas simbólicas tenham unidade com o discurso organizacional determinado e com a imagem construída pelo público de interesse com relação à organização. A respeito do contexto apresentado, Corrêa (2009) lembra que

[...] nem todo processo comunicacional de uma organização é digital ou digitalizável e nem toda TIC é adequada à proposta de comunicação integrada de uma dada organização. A comunicação digital se configura no ambiente corporativo na medida e na oportunidade em que a combinação entre proposta comunicacional e características do público tiver mais eficiência se realizada em ambiência digital (2009: 321).

Nesse sentido, é possível relacionar o que Charaudeau (2007) teoriza como sendo o quadro de referências constituído pela situação de comunicação, ao qual os indivíduos recorrem quando iniciam uma interação. Trata-se, pois, imprescindível o reconhecimento das restrições da situação de comunicação em que estão envolvidos, de forma que se subscreva um contrato de comunicação entre os atores sociais envolvidos.

Ainda, revela-se indispensável que se tenha como base para a proposição de estratégias, o plano global de comunicação e o planejamento estratégico global da organização, seja este voltado a alcançar objetivos econômicos, políticos ou sociais, contanto que tenham o intuito de viabilizar uma comunicação estratégica eficiente/excelente. Corrêa (2009) evidencia algumas das vantagens competitivas decorrentes do uso coerente de meios digitais, a saber;

[...] agregação de valor à relação ambiente-usuários; construção e sustentação de relacionamento e de comunidades de interesse; promoção de trocas interpessoais e intergrupais; acesso e uso de informações utilitárias e de informações para ação/decisão; criação de meio acelerador/facilitador dos fluxos de trabalho; geração de espaços de aquisição de conhecimento, entre outros (2009: 329).

Nessa direção, avanço para a reflexão da visibilidade midiática das ações e práticas organizacionais como estratégia de legitimação na ambiência digital, esta caracterizada pelas novas formas de interação e sociabilidade. Entenda-se por legitimação neste estudo, a explicação, a justificação da ordem das organizações e a representação das mesmas nos mídia, mais especificamente nos digitais, perante o cenário social. Jürgen Habermas (1979) considera a legitimidade como sendo a preservação, na esfera social, de uma identidade organizacional normativamente determinada. A pretensão consiste em sustentar os valores 
constitutivos dessa identidade e defender o porquê da existência e de sua atuação na sociedade.

\section{Uisibilidade midiática e legitimação organizacional na contemporaneidade}

Para o entendimento das lógicas de legitimação das organizações por meio de processos de visibilidade midiática é válido, primeiramente, fazer alguns apontamentos a respeito do processo de midiatização da sociedade. A partir dos postulados de Muniz Sodré (2007),

\footnotetext{
Por midiatização, entenda-se, assim, não a veiculação de acontecimentos por meios de comunicação (como se primeiro se desse o fato social temporalizado e depois o midiático, transtemporal, de algum modo), e sim o funcionamento articulado das tradicionais instituições sociais com a mídia. [...] uma mutação sócio-cultural centrada no funcionamento atual das tecnologias de comunicação (2007: 17).
}

Em tal contexto, novas estruturas de informação, tecnologias de comunicação e formas de interação caracterizam uma sociedade em que a economia fundamenta-se não mais na indústria, mas na informação. Também, Duarte (2009) aponta que as organizações contemporâneas mostram-se mais flexíveis e abertas à atuação em redes muitas vezes efêmeras; características que evidenciam a dinamicidade do processo comunicacional.

Isso é corroborado à medida que as formas de sociabilidade e processos sociais específicos passaram a se desenvolver segundo as lógicas da mídia (BRAGA, 2007 apud BARICHELLO, 2009). O potencial da mídia digital, aqui entendida como dispositivo técnico e fluxo comunicacional, pode ser também considerada uma ambiência própria onde a realidade é gerada e os modos de relacionamento na sociedade se transformam. Nesse contexto, Sodré (2007: 21) introduz "o conceito do bios midiático, que é a configuração comunicativa da virtualização generalizada da existência" [...] "é a sociedade midiatizada enquanto esfera existencial capaz de afetar as percepções e as representações correntes da vida social."

A midiatização, pois; caracteriza-se por valer-se de uma conjuntura sociotécnica em que os indivíduos são levados em consideração, visto que se tratam de sujeitos capazes de interpretação, resposta e modificação das propostas organizacionais. Revela-se evidente que a evolução dos meios de comunicação digitais possibilita outras formas de interação, assim como no decorrer da história a visibilidade adquire formas particulares, mostrandose atualmente representada pela mídia, esta considerada esfera de visibilidade pública. 
Podemos transpor o pensamento de Thompson (1998) do campo do poder político para o sistema da organização e da sociedade contemporânea, quando faz apontamentos sobre alguns aspectos modificados com o desenvolvimento das tecnologias comunicacionais. Graças à comunicação mediada, as audiências aumentaram e passaram a não estarem mais fisicamente presentes, logo; percebeu-se que a visibilidade pública não mais requeria co-presença. Muitas pessoas passaram a poder ter informações sobre poucos, uns poucos podem atualmente aparecer diante de muitos e aqueles que detêm o poder são submetidos a um regime de visibilidade maior do que aqueles sobre quem o poder é exercido.

Nesse sentido, a relação é válida na medida em que aponta para as mudanças da natureza da visibilidade e se percebe que os modos de administrá-la também evoluíram. A dificuldade de controlar a visibilidade através da mídia aumentou, visto que os fatos e ações propostas pelas organizações estão, permanentemente, expostos à visão e à construção social de sentidos pelos públicos e por instituições; assim como a comunicação midiática está em processo contínuo de transformação devido à emergência de novas tecnologias. Barichello e Scheid indicam que

Depois das transformações na comunicação trazidas pela escrita, pelo desenvolvimento da tipografia e da imprensa, pelos meios eletrônicos de comunicação, vivemos as possibilidades comunicativas proporcionadas pelo uso da Internet e dos meios digitais (2007: 7).

A partir daí, pode-se visualizar um novo lugar de visibilidade e legitimação organizacional que compreende também espaços possíveis pelas novas tecnologias. Há o desenvolvimento de novas ambiências de interação e sociabilidade, os quais ampliam as possibilidades de interpretação e resposta dos sujeitos que dizem respeito à sua relação com as organizações da contemporaneidade. É o meio digital, como a Internet, que imprime novas características às relações de comunicação, a saber, a negociação de sentidos entre as organizações e seus públicos, que mais adiante desenvolverei sob os dois tipos possíveis de interação: mútua e reativa, resultado dos estudos de Alex Primo (2000).

Nesse contexto, vale reforçar a importância da rede formada pela Internet para o compartilhamento de informações entre as organizações e seus públicos de interesse. Para as Relações Públicas, a mídia digital refere-se a mais um espaço e aparato tecnológico pelo qual estratégias planejadas de visibilidade, com vistas à legitimação, podem ser empreendidas com a finalidade de interagir com a sociedade. Desse modo, será possível por meio das ações de Relações Públicas, com base nos objetivos organizacionais, a 
visualização de oportunidades e riscos à sustentabilidade desta no mercado competitivo e inovador, além de promover a integração organização-públicos. Ressaltam-se aí as palavras de Grunig (2009), que se refere à importância e ao fato de as Relações Públicas agregarem valor às organizações, por meio das quais se age de forma integrada aos processos organizacionais e investe-se em relacionamentos contínuos que trazem retorno incomensurável à empresa ao longo dos anos.

Levando em conta que a visibilidade midiática depende da habilidade das organizações em informar e comunicar seus atos em diferentes mídias e que é fator de sobrevivência e evolução, a comunicação digital deve ser considerada um espaço em que as organizações e seus públicos negociam estratégias, significados e sentidos.

Com relação a isso, pode ser trazida a revisão dos estudos tradicionais de interação humana feita por Primo (2000 apud BARICHELLO; SCHEID, 2007: 10) voltando-se para a interação no ambiente informatizado. Segundo esse autor, em sistemas de interação mútua a comunicação é negociada, definida durante o processo de comunicação, ou seja; a relação é construída constantemente pelos interagentes num processo interpretativo não pré-determinado. Isso pode ser notado pelas propostas organizacionais em estratégias comunicativas num portal de Internet, blog corporativo e noutros dispositivos digitais de uso da mesma. Por outro lado, a interação reativa ocorre por meio de espaços construídos pelos sujeitos, tais como comunidades em redes de relacionamento e sites de microblogs a saber, o Twitter - como forma de propor novas interpretações e compartilhar interesses comuns.

Com relação às formas inovadoras de comunicação digital, Corrêa (2009) pontua:

Falamos de uma multiplicidade de outros recursos de base digital que podem ser utilizados conforme a ação planejada, o conteúdo das mensagens, a característica do público e as respostas esperadas. É aqui que se percebe o exercício da arte de comunicar sem a perda da eficácia (2009: 331).

A ambiência dos meios de comunicação digitais apresenta-se, pois; como o novo local onde a visibilidade das organizações é edificada - via estratégias que articulam modos de ver - e na qual a cena das novas lógicas de legitimação é construída de maneira interativa. A importância desse novo espaço de relação sócio-interativa na contemporaneidade se dá pelo imenso poder simbólico dessas relações que se estabelecem no ambiente virtual, atreladas às práticas socioculturais dos indivíduos.

É por meio das práticas de linguagem e de interação comunicacional que a legitimação resulta. Nesse sentido, não basta estar na mídia para legitimar-se. Revela-se 
imprescindível pensar o relacionamento com os públicos afetos à organização. Baseadas na linguagem - principal celeiro das experiências coletivas - as organizações lutam pela legitimação e consolidação de uma imagem positiva e favorável junto à sociedade. Com relação à linguagem, Charaudeau (2007) explica que é por meio dela que o mundo torna-se inteligível ao olhar do homem, cujo saber está estruturado em conhecimentos e crenças; a partir dos quais o sujeito faz apreciações, interpretações e julgamentos sobre o mundo de modo a levar o outro a compartilhá-los. A última parte da estrutura refere-se às representações, que se baseiam na observação empírica das trocas sociais e que fabricam um discurso de justificativas produtor de um sistema de valores.

Em face disso e da necessidade de objetivação de significados pelos indivíduos exteriorização das vivências, práticas e representações - com relação à determinada organização, torna-se evidente o fato de que são os sujeitos que tornam possível a existência organizacional e de que estas necessitam permanentemente justificar suas ações, ou seja, legitimar-se junto aos atores sociais.

Nesse ponto, revela-se imperioso relacionar a potencialidade mediadora dos meios de comunicação, mais especificamente os digitais possibilitados pelos sistemas da Internet, e o papel das Relações Públicas na mediação de relações com os stakeholders e na viabilização constante de ações que garantam visibilidade midiática favorável à organização. Por meio dos recursos tecnológicos disponíveis na rede virtual, tais como Twitter, Facebook e Orkut; os Relações Públicas buscam, de maneira planejada e intencional, aproximar-se e mediar os interesses comuns numa ambiência construída e compartilhada por ambos, na qual os indivíduos também apresentam-se como agentes de mediação e midiatização.

O processo de edificação da legitimação apresenta-se, pois, vinculado à mídia considerada como esfera de visibilidade. Nesse sentido, a visibilidade midiática na sociedade contemporânea é o novo local da cena de legitimação, considerando que, na sociedade atual, não só é necessário legitimar os atos das organizações, mas também tornálos legítimos por intermédio desses novos suportes de visibilidade (BARICHELLO, 2002).

\section{Considerações Finais}

Com as novas possibilidades de interação oportunizadas pelo avanço das tecnologias da informação e comunicação, os processos de construção de visibilidade midiática e de legitimação organizacional na sociedade também sofreram modificações. 
O ambiente digital, na contemporaneidade, apresenta-se, portanto; como mais um lugar de disputa de estratégias, significados e sentidos entre as organizações e os públicos de interesse. Tais disputas são viabilizadas graças a espaços criados por ambos interagentes, que buscam apresentar e defender seus interesses. A evolução das TICs, portanto, modificou e tornou mais interativa a forma como a informação é gerada, compartilhada e processada pelos atores sociais.

Cabe, pois, às Relações Públicas potencializar esses espaços com o empreendimento de ações planejadas e estratégicas aliadas ao plano global de comunicação corporativa. Para isso, faz-se necessário criar - também - um sistema eficiente de gerenciamento para tais ações, no sentido de garantir visibilidade e legitimação organizacional nessa configuração de bios midiático, caracterizada pelo desenvolvimento reticular, pela interatividade e pela dinamicidade da comunicação contemporânea.

\section{Referências Bibliográficas}

BARICHELLO, E. M. da R. "Apontamentos sobre as estratégias de comunicação mediadas por computador nas organizações contemporâneas". In: KUNSCH, M. M. K. (Org.). Comunicação Organizacional: Históricos, Fundamentos e Processos. Vol. I. São Paulo: Saraiva, 2009: 337-353.

“A construção da visibilidade institucional pela mídia”. In: BARICHELLO, E. M. da R (Org). Comunicação Midiática. Santa Maria, RS: FACOS/UFSM, 2002: 33-55. Comunicação e comunidade do saber. Santa Maria, RS: FACOS/UFSM, 2001.

; SCHEID, D. “Apontamentos sobre a construção da visibilidade das instituições na Internet a partir de um cenário de midiatização da sociedade”. In: E-Compós - Revista da Associação Nacional dos Programas de Pós-Graduação em Comunicação. V.10, 2007. Disponível em <http://www.compos.org.br/seer/index.php/e-compos/article/viewFile/207 /208>. Acessado em: 13/10/2009.

CHARAUDEAU, P. Discurso das mídias. 1. Ed., 1ª reimp. São Paulo: Contexto, 2007. 
CORRÊA, E. S. "Comunicação digital e novas mídias institucionais". In: KUNSCH, M. M. K. (Org.). Comunicação Organizacional: Históricos, Fundamentos e Processos. Vol. I. São Paulo: Saraiva, 2009: 317-335.

DUARTE, J; MONTEIRO, G. "Potencializando a comunicação nas organizações". In: KUNSCH, M. M. K. (Org.). Comunicação Organizacional: Históricos, Fundamentos e Processos. Vol. I. São Paulo: Saraiva, 2009: 333-359.

FERRARI, M. A. “Teorias e Estratégias de Relações Públicas”. In: KUNSCH, M. M. K. (Org.). Gestão estratégica em comunicação organizacional e relações públicas. São Caetano do Sul, SP: Difusão Editora, 2008: 77-90.

GRUNIG, J. E.; FERRARI, M. A.; FRANÇA, F. Relações Públicas: teoria, contexto e relacionamentos. $1^{\text {a }}$ Ed. São Caetano do Sul, SP: Difusão Editora, 2009.

KREPS, Gary L. La Comunicación em las Organizaciones. Estados Unidos: Addison Wesley Iberoamericana, 1995.

SODRÉ, M. Sobre a episteme comunicacional. In: Matrizes - Revista do Programa de Pós Graduação em Ciências da Comunicação da Universidade de São Paulo. São Paulo, nº1, out. 2007. Disponível em: <http://www.usp.br/matrizes/MATRIZes_01_01_ por.php>. Acessado em: 25/10/2009.

THOMPSON, John B. A mídia e a modernidade. Uma teoria social da mídia. Petrópolis, RJ: Vozes, 1998. 